\title{
Fetal Cerebral Monitoring During the Second Stage of Labor
}

\author{
LEONARD NASTASE ${ }^{1,2 *}$, MONICA LUMINOS ${ }^{1,3}$, GHEORGHITA JUGULETE ${ }^{1,3}$, MADALINA MARIA MERISESCU $^{1,3}$, \\ SILVIA MARIA STOICESCU1,2 \\ ${ }^{1}$ Carol Davila University of Medicine and Pharmacy, 37 Dionisie Lupu Str., 020021, Bucharest, Romania \\ ${ }^{2}$ National Institute for the Mother and Child Health Alessandrescu Rusescu, Polizu Maternity, 38-52 Gheorghe Polizu Str., 011062, \\ Bucharest, Romania \\ ${ }^{3}$ National Institute of Infectious Diseases Prof. Dr. Matei Bals, 1 Dr. Calistrat Grozovici Str., 021105, Bucharest, Romania
}

\begin{abstract}
The moment of perinatal hypoxic injury is still difficult to be identified by current monitoring techniques. Recent studies highlights that the effectiveness of therapy in hypoxic ischemic encephalopathy, such as therapeutic hypothermia and antioxidant agents, is determined by the time elapsed from the moment of injury to the begining of intervention. Twenty six term newborns were analyzed, 13 from vaginal delivery and 13 extracted by cesarean section. The group selection criteria were: term pregnancy (gestation age $\geq$ 37 weeks), normal labor, cranial presentation, without fetal malformations and normal neonatal transition. We believe that additional fetal brain monitoring (NIRS and/or aEEG) can predict fetal brain events due to severe prepartum acidosis. Intrauterine fetal cerebral saturation is at the lower limit of postnatal neonatal cerebral saturation. FTOE is maximum during vaginal or cesarian section delivery compared to those in the first 10 min of life. The mode of delivery does not significantly affectFTOE or placental oxygen blood supply. Because the hypoxic - ischemic injury has accurred during late decelerations, consider it necessary to identify hypoxic markers prior to detection of this typ of FHR .
\end{abstract}

Keywords: second stage of labor, fetal cerebral oxygen saturation $\left(\mathrm{rSO}_{2}\right)$, fractional cerebral tissue oxygen extraction (CFTOE), fetal hypoxia, newborn

The moment of perinatal hypoxic injury is still difficult to be identified by current monitoring techniques. Recent studies highlights that the effectiveness of therapy in hypoxic ischemic encephalopathy, such as therapeutic hypothermia and antioxidant agents, is determined by the time elapsed from the moment of injury to the begining of intervention [1,2]. Animal studies had established the optimal time to initiate therapy within the first $6 \mathrm{~h}$ of hypoxic ischemic injury [3]. The applicability within the first 6 hours in human studies has been extrapolated but often this does not coincide with the moment of injury. Near Infrared Spectroscopy (NIRS) and amplitude-integrated electroencefalography ( $a E E G$ ) monitoring during neonatal transition have the potential to bring informations about fetal distress and help early tratment, but often the results are inconclusive [4]. An explanation for these results could be the late initiation of terapy in late-stage post injury even in the presence of immediate postnatal monitoring. To sum up, we believe that additional fetal brain monitoring (NIRS and/or aEEG) can predict fetal brain events due to severe prepartum acidosis.

\section{Experimental part}

Material and method

Twenty six term newborns were analyzed, 13 from vaginal delivery and 13 extracted by cesarean section. The group selection criteria were: term pregnancy (gestation age $\geq 37$ weeks), normal labor, cranial presentation, without fetal malformations and normal neonatal transition. Vaginal delivered newborns were monitorised for cerebral saturation during delivery and immediately postpartum. At those extracted by cesarean section the cerebral oxygenation was evalueted straight away. The blood gas analysis was performed in all patients from the sample within the umbilical artery. Cerebral blood oxigenation was evaluated by $\mathrm{SaO}_{2}$ and $\mathrm{PaO}_{\text {2 }}$.

NIRS measurements were performed with inVOS 5100 $\mathrm{C}$ (Somametics, Covidien) by placing the sensor consisting of one diode and two optodes located at $3.5 \mathrm{~cm}$ and respectively $4 \mathrm{~cm}$ from the diode.

The neonatal sensor of NIRS has sizes of $50 \times 20 \times 1.5$ $\mathrm{mm}$, its sterile, disposable and placed under sterile conditions by an obstetrician at pregnant woman after the amniotic membrane rupture and the dilation of cervix $\geq 5$ $\mathrm{cm}$. The sensor is attached to the fetal scalp by the pressure of maternal tissues adjacent to the fetal head. Due to the NIRS penetration to the cerebral cortex, the exact position of the sensor is not critical, but the face and ears should be avoided. This should be checked by the obstetrician. Recorded NIRS values has been individually analyzed and only those with full SSI (Signal Strength Indicator) signal has been validated. In all the cases studied, prior to antenatal and postnatal measurements, the written and verbal agreement was obtained with the informed consent of each pregnant woman. There were no reported difficulties in placing the sensors on the fetal scalp. Pregnant women did not report discomfort during fetal NIRS monitoring. Procedures required for this monitoring have not interfered with routine care required during labor or delivery. No lesions due to transvaginal insertion, fetal head application, or removal of the NIRS sensor occurred in both maternal tissues and fetal tissues. Also, the light emitted by NIRS is below the standard internationally approved safety limits for exposure to LASER light of the eyes or tegument.Thus, NIRS monitoring is free of fetal tissue damage.

\section{Difficulties in NIRS monitoring at the fetus and potential causes of errors}

Inevitably, in the case of direct fetal monitoring and especially during contractions, we will encounter difficulties due to indirect and limited access, the movement of sensors applied to the fetal scalp and the important pressures exerted during the contractions of the uterus. In our study, they cause measurement difficulties and increased incidence of artifacts. An important source 
of this technical failure is the weak contact between the optodes and the fetal scalp due to either rapid head descent or maternal position change. A weak contact can be detected by observing steep changes in the value of the SSI signal. Regarding the accuracy of the displayed NIRS value, it may vary by the distance between optodes and the diode can be read as variations of the chromophores $(\mathrm{OxiHb}$ and $\mathrm{HHb})$ or the pressure exerted on them.The NIRS-INVOS program is set to provide a constant wavelength. Changing diode and optode distances may occur during contractions. INVOS $5100 \mathrm{C}$ can not detect and attenuate very small and gradual changes in the position of the optodes that are accompanied and the change in the total optical wavelength. Some researchers have observed in a dead fetus similar changes in fetal cerebral $\mathrm{rSO}_{2}$ and dynamics to that of a living fetus [5].These changes are explained by the optodes motion artifacts and / or the pressure on them during contractions, but the use of newer NIRS techniques allows the attenuation of variations. NIRS with modulated intensity highlights variations in wavelengths during contractions of up to $6 \%$, which with current techniques become insignificant to be sources of error $[6,7]$.

\section{Results and discutions}

A prospective observer study has been conducted in the labor room in pregnant women without associated pathology.We studied 13 human fetuses at term in the second stage of labor, with an average of 30 min antenatal (10-100 min antenatal) in the Polizu Clinical Hospital. Their anthropometric data after birth were (table 1): mean age of gestation (GA) 39 weeks, mean BW $3474 \mathrm{~g}$, equal proportions between male and female. The evaluation of the acid-base balance at birth (table 2.) in the umbilical artery from the umbilical cord $(\mathrm{pH}=7.22, \mathrm{BE}=-8.2 \mathrm{mmol}$ $/ \mathrm{L}, \mathrm{pO}_{2}=20 \mathrm{mmHg}, \mathrm{pCO}_{2}=53 \mathrm{mmHg}$, lactate $=4.9 \mathrm{mg}$ ( dL) shows the absence of severe cases of fetal suffering in the analyzed cases.In one case, the birth was instrumentalised by vaccum asspiration, and the blood gas analysis revealed moderate acidosis $(\mathrm{pH}=7.08, \mathrm{BE}=$ $14.6 \mathrm{mmol} / \mathrm{L}$, lactate $=7.5 \mathrm{mmol} / \mathrm{L}$ ). In one case, Nitrous oxide $\left(\mathrm{N}_{2} \mathrm{O}\right)$ mixed with $\mathrm{O}_{2}$ - an inhaled anesthetic gas consisting of two equal proportions of $\mathrm{N}_{2} \mathrm{O}$ and $\mathrm{O}_{2}$, was used as a method of maternal analgesia in labor, at which fetal brain $\mathrm{rSO}_{2}$ values were observed during and between contractions, and they were similar to cases without maternal analgesia.

During stage II contractions, cerebral oxygenation was on average 15.8 (15-18), and between contractions $\mathrm{rSO}_{2}$ rises sharply (1-3 $\mathrm{min}$ ) to a peak of 53.3 (42-56). During delivery, fetal cerebral $\mathrm{rSO}_{2}$ decreases to the minimum values of 16 (15-19) similar to the values measured during contractions.

At rest, the intrauterine pressure is approximately 10 $\mathrm{mmHg}$, which is also transmitted to the intervillous space $(10 \mathrm{mmHg})$. During contraction, intramyometrial pressure (IMP) increases and flow through the spiral arteries decreases from $70 \mathrm{mmHg}$ to zero when the intrauterine pressure exceeds $35 \mathrm{mmHg}[8,9]$. With the cessation of contraction the flow through the uterine spiral arteries, it resumes and returns to normal at the end of the contraction $[9,10]$. This is reflected in the fetal cerebral circulation by a decreased fetal $\mathrm{rSO}_{2}$ at rest to an average of $53.3 \%$ (42$62 \%$ ), to a value of $16.3 \%$ (15-21\%) during the complete contraction, and returning to the initial value at the end of contraction (fig.1).

\begin{tabular}{|l|l|l|l|}
\hline & $\begin{array}{l}\text { Vaginal Delivery } \\
\text { (no. 13) }\end{array}$ & $\begin{array}{l}\text { C-section delivery } \\
\text { (no. 13) }\end{array}$ & $\mathbf{p}<\mathbf{0 . 0 5}$ \\
\hline Gestational Age (weeks) & $39(37-40)$ & $38(37-40)$ & n.s \\
\hline Birth Weght (g) & $3474(2900-3900)$ & $3270(2900-4300)$ & n.s \\
\hline Male/Female & $6 / 7$ & $8 / 5$ & n.s \\
\hline Apgar Score (SA) & $8.6(6-9)$ & $8.4(7-9)$ & n. s. \\
\hline
\end{tabular}

Table 1

THE GROUP'S CHARACTERISTICS

\begin{tabular}{|l|l|l|l|}
\hline Caracteristici & Vaginal Delivery (no. 13) & $\begin{array}{l}\text { C-section delivery } \\
\text { (no. 13) }\end{array}$ & $\mathbf{p}<0.05$ \\
\hline pH & $7.22(7.08-7.34)$ & $7.34(7.17-7.45)$ & 0.039 \\
\hline BE (mmol/L) & $-8.2((-1.5)-(-14.6))$ & $-2.6(-7-0.7)$ & 0.005 \\
\hline pO2 (mmHg) & $18.4(8-29)$ & $21.1(10.5-28.1)$ & 0.24 \\
\hline pCO2 $(\mathrm{mmHg})$ & $54.2(39-65)$ & $43.6(32.7-62.9)$ & 0.043 \\
\hline Lactat $(\mathrm{mmol} / \mathrm{L})$ & $5.0(3-7.5)$ & $2.4(0.7-4.6)$ & 0.013 \\
\hline
\end{tabular}

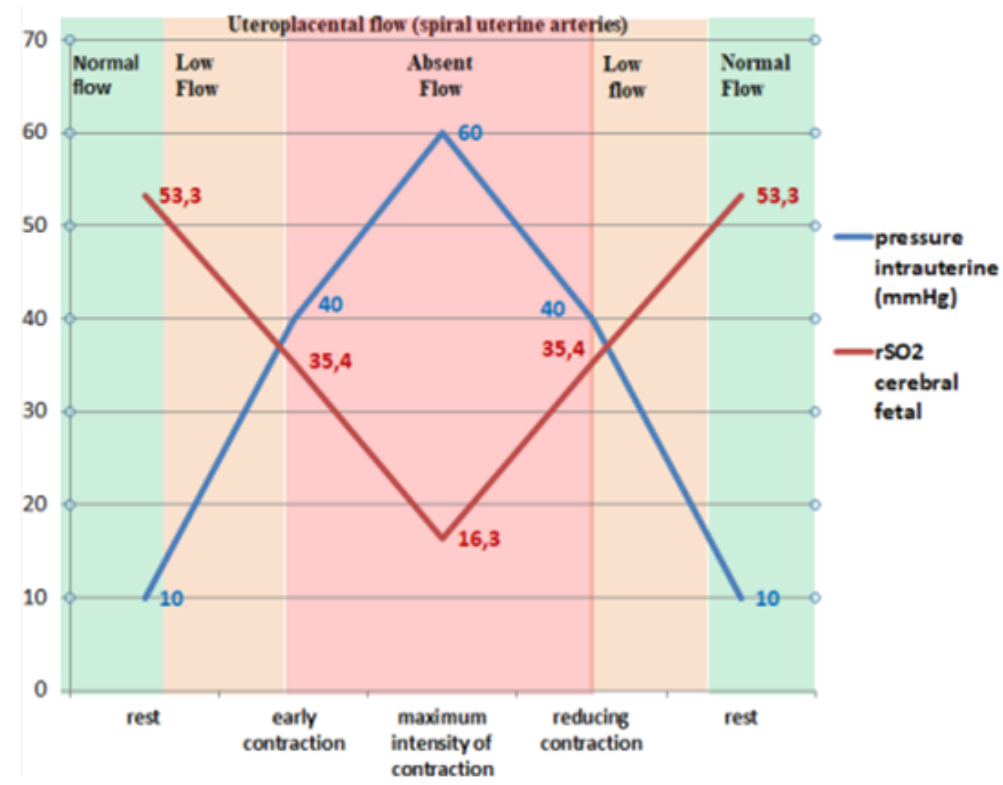

Table 2

ACID-BASE BALANCE
Fig.1. The dynamics of fetal brain oxygenation during uterine contractions 


\begin{tabular}{|l|l|l|l|l|}
\hline & $\begin{array}{l}\text { Vaginal delivery } \\
(\mathrm{nr} .13)\end{array}$ & $\begin{array}{l}\text { Cesarian section } \\
(\mathrm{nr} .13)\end{array}$ & p value & All patients \\
\hline rSO2 cerebral (\%) & $17.2(15-19)$ & $16.8(15-30)$ & 0.33 & $16.9(15-30)$ \\
\hline FTOE cerebral (\%) & $0.73(0.61-0.75)$ & $0.71(0.33-0.78)$ & 0.33 & $0.72(0.57-0.81)$ \\
\hline ctO2 (mL/dL) & $7.9(2-12.2)$ & $7.01(1.6-13.6)$ & 0.36 & $(1.6-13.6) 7.5$ \\
\hline $\mathrm{SaO}(\%)$ & $35.1(10.8-60)$ & $40.0 \%(8.6-69.1)$ & 0.18 & $37.2(8.6-69.1)$ \\
\hline
\end{tabular}

Tabel 3

CEREBRAL OXYGENATION AND CEREBRAL FRACTIONAL TISSUE OXYGEN EXTRACTION (CFTOE) IN VAGINAL VERSUSCESARIAN SECTION DELIVERY
It is noted that intrauterine fetal cerebral rSO2 between contraction (at rest) is approximately equal to the normal range of postnatal neonatal cerebral saturation. The flow of the spinal arteries that supply the placenta is stopped during maximum contraction (intraamniotic pressure 40$60 \mathrm{mmHg}$ ) similar to what happens during the delivery, a confirmed phenomenon by the $\mathrm{rSO}_{2}$ that has a minimum value of $16.3 \%$ (15-21\%) during contraction, delivery and immediately postpartum. Fetal cerebral saturation $\left(\mathrm{rSO}_{2}\right.$ ) is mainly determined by cerebral blood flow and oxygen intake.

Special vascular organization in the uterine wall with the perpendicular disposition of the spiral arteries and parallel of the veins, facilitates vein closure during contraction preventing the extortion of blood from the intervilous space [8]. Thus, even at intrauterine pressures above $60 \mathrm{mmHg}$, the diastolic notch at the level of the umbilical vessels does not occur, and their resistance indices remain stable in labor and allow a permanent fetoplacental exchange [11]. We can say that $\mathrm{rSO}_{2}$ decreases based on the reduced oxygen intake to the fetus that is interrupted with each contraction, but this is a common phenomenon for a normal fetus (such as breathing interruption for a few seconds). If contractions become too frequent, they can lower the fetal oxygen supply needed for the following contractions and can put the fetus in danger of hypoxia. The same risk of hypoxia is experienced by fetuses who already have significant pathologies that affect their oxygen resources and will not normally tolerate frequency, duration or intensity of normal contractions.

A group of 13 neonates extracted via C-section (table 2) has been studied comparatively with the above group, and in the last one $\mathrm{rSO}_{2}$ was been measured immediately after cesarean delivery and after premature clamping of umbilical cord. This group includes clinically-assessed newborns with good intrauterine and postnatal development and by the blood gas analysis from the arterial vessel of the umbilical cord (table 2). The anthropometric and biochemical characteristics are without significant differences between the two groups. Thus, it was observed that cerebral oxygenation in the first minute of life, in this category of newborns, has values of 16.8 (15-30) similar to the values measured in delivery during natural birth (table 3). This suggests that cesarean section procedures, such as uterine incision and fetal pull-out procedures have fetal cerebral haemodynamic effects equivalent to those during a contraction during natural delivery. Some studies show that in the case of extraction by cesarean with labor the $\mathrm{pH}$ is similar ( $\mathrm{pH}=7.25$ ) but $\mathrm{pCO}$ is higher and $\mathrm{pO}$ is lower compared to natural birth [12]. Repeated contractions in normal labor prior to cesarean delivery result in significant metabolic stress on the fetus. In the absence of labor prior to cesarean extractions, the blood gas analysis in the umbilical artery may be close to those of the mother (higher $\mathrm{pH}, \mathrm{pOv}, \mathrm{BE}$ and bicarbonate, and respectively lower $\mathrm{pCO}_{2}$ ) $[13,14]$. Our results show significantly higher $\mathrm{pH}$ in the case of C-sections and this is due to the absence of labor. In the case of natural births the right shift of the $\mathrm{O}, \mathrm{Hb}$ dissociation curve, the low $\mathrm{pH}$ works by lowering the affinity of the oxygen allowing it to increase its release to the tissue or cerebral level during metabolic acid stress during contractions. Extraction time is too short for biochemical changes to occur, so biochemical parameters (e.g pH) remain unchanged but cerebral hemodynamic changes occur that explain similar values of cerebral oxygenation during delivery or cesarian section extraction although $\mathrm{pH}$ is different in the two conditions. Cerebral fractional cerebral tissue oxygen extraction (CFTOE) is slightly increased in the case of natural births 0.65 vs. 0.62 but insignificantly statistically. The ct02 does not statistically influence the FTOE, which indicates the placental and fetal blood oxygen reserve are sufficient for normal labor or cesarian section (table 3). Therefore the mode of delivery does not influence cerebral blood flow status.

When measuring fetal cerebral $\mathrm{rCSO}_{2}$ in the second stage of labor, in the case of vaginal delivery, the term newborns showed a gradual decrease over the last 30 minutes until delivery with a minimum in delivery, and a gradual increase after birth in the first 10 min Previous studies show good protection of the fetal head during contractions and deliverys by direct measurements of intracranian and intraamniotic pressure on human fetuses with hydrocephalus incompatible with life $[15,16]$, and indirect measurements like cerebral flow, cerebral oxygenation and cerebral electrical activity of the fetus. Thereby in stage II of labor, the cerebral blood volume increases [16] and the EEG route is maintained $[17,18]$ within normal limits during contractions or delivery. This

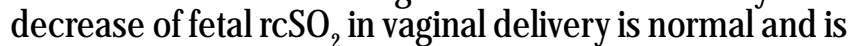
not caused by mechanical factors of fetal cephalic compression or the effects of acidic and basic biochemical factors on cerebral flow. In conclusion, it remains to be studied utero-placental oxygen intake using fetal pulse oximetry and cerebral metabolism.

There is little data to show the link between FHR (fetal heart rate) and cerebral fetal oxygenation. From the three main types of FHR deceleration (early, variable and late), late ones have the greatest clinical significance in predicting hypoxia and fetal acidosis. Previous stage II labor studies shows that the $\mathrm{O}_{2} \mathrm{Hb}$, deoxiHb, and total haemoglobin dynamics are the same during contraction in the two groups studied (normal-control and latedeceleration contractions). However, in the time after the contraction there was a significant decrease in $02 \mathrm{Hb}$ and a important increase in deoxyhaemoglobine in the second group, as well as the collapse of FHR [19,20]. This increase in deoxiHb associated with low FHR is believed to be due to a deoxygenated placental blood bolus coming from the umbilical vein [21]. 


\section{Conclusions}

Cerebral oxygenation decreases during contractions due to low oxygen in the utero-placental blood supply, while placental-fetal perfusion is permanently maintained. This is a physiological phenomenon of fetal tissue hypoxic preconditioning to support delivery. Under natural labor conditions, placental oxygen supplies during contraction are sufficient to prevent anaerobic metabolism and the occurrence of lactic (metabolic) acidosis.

Intrauterine fetal cerebral saturation is at the lower limit of postnatal neonatal cerebral saturation. FTOE is maximum during vaginal or cesarian section delivery compared to those in the first $10 \mathrm{~min}$ of life. The mode of delivery does not significantly affect FTOE or placental oxygen blood supply.

Because the hypoxic - ischemic injury has accurred during late decelerations, consider it necessary to identify hypoxic markers prior to detection of this typ of FHR .

\section{References}

1.EBRU ERGENEKON. Therapeutic hypothermia in neonatal intensive care unit: Challenges and practical points. J Clin Neonatol 2016, 5:817

2.*** COMMITTEE ON FETUS AND NEWBORN, PAPILE LA, BALEY JE, BENITZW, CUMMINGSJ, CARLO WA, et al. Hypothermia and neonatal encephalopathy. Pediatrics 2014;133:1146-50.

3.KYOHEI YAMAGUCHI, CHRISTOPHER A. LEAR, MICHAEL J . BEACOM, TOMOAKI IKEDA, ALISTAIR J. GUNN, LAURA BENNET. Evolving changes in fetal heart rate variability and brain injury after hypoxia ischaemia in preterm fetal sheep. The Journal of Physiology 30 January 2018 .https://doi.org/10.1113// P275434

4.PICHLER G, AVIAN A, BINDER C, ZOTTER H, SCHMOLZER GM, MORRIS N, MÜLLER W, Urlesberger B: aEEG and NIRS during transition and resuscitation after birth: promising additional tools; an observational study. Resuscitation 2013;84:974-978.

5.HAMILTON, R. J., O'BRIEN, P. M. S., WICKRAMASINGHE, Y. A. B. D. \& ROLFE, P. 1995 Intrapartum fetal cerebral near infrared spectroscopy: apparent change in oxygenation demonstrated in a non-viable fetus. Br. J. Obstet. G'naecol. 102, 1004-1007

6.0'BRIEN P.J, S. LAWRENCE, R. WATSON et al. Intrapartum fetal cerebral near infrared spectroscopy: apparent change in oxygenation demonstrated in a nonviable fetus. BJ OG 1996

7.S E NICKLIN, I A-A HASSAN, Y A WICKRAMASINGHE, S A SPENCER. review The light still shines, but not that brightly? The current status of perinatal near infrared spectroscopy. Arch Dis Child Fetal Neonatal Ed 2003;88:F263-F268

8.W ANG I , SHUANG ZHAO. Vascular Biology of the Placenta. Louisiana State University San Rafael (CA): Morgan \& Claypool Life Sciences; 2010.
9.FLEISCHER A, ANYAEGBUNAM AA, SCHULMAN H, FARMAKIDES $G$, RANDOLPH $G$. Uterine and umbilical artery velocimetry during normal labor. American J ournal of Obstetrics and Gynecology 157(1): 40-3August 1987

10.C. O. FIGUEIRA, F. G. SURITA, M. S. DERTKIGIL, S. L. PEREIRA, J . R. BENNINI J R., S. S. MORAIS, J. MAYRINK, AND J. G. CECATTI. Fetal Hemodynamic Parameters in Low Risk Pregnancies: Doppler Velocimetry of Uterine, Umbilical, and Middle Cerebral Artery The Scientific World J ournal Volume 2016 (2016), Article ID 1693704, 7

11.MIHU D, DICULESCU D, COSTIN N, MIHU CM, BLAGA L, CIORTEA R, MALUTAN A.Applications of Doppler ultrasound during labor. Med Ultrason. 2011 J un;13(2):141-9

12.HAGHSHENAS MOJAVERI M, AKBARIANRAD Z, ZAHED PASHA Y, RAHIMI R. The Effect of mode of delivery on the umbilical artery $\mathrm{pH}$. CJP. 2016; 2 (1) :113-117

13.ARMSTRONG, L., \& STENSON, B. J. (2007). Use of umbilical cord blood gas analysis in the assessment of the newborn. Archives of Disease in Childhood. Fetal and Neonatal Edition, 92(6), F430-F434. 14.TUULI MG, STOUT MJ, SHANKS A, et al. Umbilical cord arterial lactate compared with $\mathrm{pH}$ for predicting neonatal morbidity at term. Obstet Gynecol 2014; 124:756.

15. HEYBORNE KENT D. A Systematic Review of Intrapartum Fetal Head Compression: What Is the Impact on the Fetal Brain? Am J Perinatol Rep 2017;7:e79-e85.

16.REFIKA GENÇKOYUCU, NURDAN DEMIRCI. Effects of pushing techniques during the second stage of labor: A randomized controlled trial. Taiwanese Journal of Obstetrics and Gynecology. Volume 56, Issue 5, October 2017, Pages 606-612

17.FRASCH MG, DUROSIER LD, GOLD N, CAO M, MATUSHEWSKI B, KEENLISIDE L, et al. Adaptive shut-down of EEG activity predicts critical acidemia in the near-term ovine fetus. Physiol Rep (2015) 3(7) 18.WANG, XIAOGANG; DUROSIER, L DANIEL; ROSS, MICHAEL G; RICHARDSON, BRYAN S; FRASCH, MARTIN G. Online Detection of Fetal Acidemia during Labour by Testing Synchronization of EEG and Heart Rate: A Prospective Study in Fetal Sheep.. PLoS One; San Francisco Vol. 9, Iss. 9, (Sep 2014): e108119.

19.ALDRICH C.J , D. D'ANTONA, J. A. D. SPENCER, J. S. WYATT, D.M. PEEBLES, D. T. DELPY, AND E. O. REYNOLDS, Late fetal heart rate decelerations and changes in cerebral oxygenation measured by near infrared spectroscopy during the first stage of labour, Br. J. Obstet. Gynaecol. 102, 9-13 (1995).

20.SHOLAPURKAR SL. Categorization of Fetal Heart Rate Decelerations in American and European Practice: Importance and Imperative of Avoiding Framing and Confirmation Biases. Journal of Clinical Medicine Research. 2015;7(9):672-680. doi:10.14740/jocmr2166w.

21.MYERS R, E. MUELLER-HEUBACH, K. ADAMSONS, Predictability of the state of fetal oxygenation from a quantitative analysis of the components of late deceleration, Am. J. Obstet. Gynecol. 115, 10831094 (1973).

$\overline{\text { Manuscript received:7.05.2018 }}$ 